\title{
RITUAIS DE SAÍDA DA BANDEIRA NA FOLIA DE SANTOS REIS DO JARDIM DAS AROEIRAS EM GOIÂNIA, GOIÁS
}

\author{
SANTOS REIS FEAST FLAG OUTING RITUALS AT JARDIM DAS \\ AROEIRAS, GOIÂNIA, GOIÁS
}

\section{LOS RITUALES DE SALIDA DE LA BANDERA EN LA FOLÍA DE REYES DEL JARDIM DAS AROEIRAS EN GOIÂNIA, GOIÁS}

\section{Tito Oliveira Coelho ${ }^{1}$ Carlos Eduardo Santos Maia ${ }^{2}$}

\begin{abstract}
Resumo: O artigo enfoca os movimentos de saída da bandeira de Santos Reis do Jardim das Aroeiras em Goiânia, Goiás, festa popular de fortes raízes rurais. Discutem-se os movimentos ritualísticos de foliões em interação espacial, possibilitado determinada leitura das influências culturais no deslocamento, na mobilização e na circulação de pessoas. Aborda-se o início de uma jornada ou giro de folia de Reis, festa popular do ciclo natalino que reproduz a viagem dos Três Reis Magos do Oriente a caminho de Belém, como modo de entender o resgate de tradições rurais da relação casa-rua no contexto urbano. Dialogam-se no texto tanto com autores da Geografia como de outras ciências humanas, a fim de compreendermos as saídas de folias como festas populares. As discussões baseiam-se em referências bibliográficas e em pesquisa de campo participante.
\end{abstract}

Palavras-Chave: Festa popular, interação espacial, folias de reis, rituais, festa religiosa.

\begin{abstract}
This article focuses on the Santos Reis flag outing at Jardim das Oliveiras located in Goiânia, Goiás, a festival of strong rural roots. Marry-make's Ritualistic movements during spacial interaction is discussed, allowing a possible interpretation of its cultural influences while displacement, futhermore its mobilization and movement of people. The journey or turn of Reis feast is approached once it is a popular Christmas feast which reflets the Three Kings trip heading to Belém as a way to understand rural tradition rescue and the home-street relation in urban context. Geography authors along with other social science authors discuss in order to comprehend the flag outings as though a popular feast. Such discussions are based on bibliographic references and fieldwork.
\end{abstract}

Key Words: Popular feast, spacial interaction, De Reis feast, rituals, religious festival.

Resumen: El artículo se centra en los movimientos de salida de la bandera de los Reyes del Jardim das Aroeiras, en Goiânia, Goiás, celebración popular de fuertes raíces rurales. Se analizan los movimientos rituales de los juerguistas en la interacción espacial, permitiendo cierta lectura de las influencias culturales en el desplazamiento, en la movilización y en la circulación de personas. Además, se aborda el comienzo de un

\footnotetext{
${ }^{1}$ Doutor em Geografia pelo IESA/UFG, Prof. Apoio Técnico Pedagógico da Secretaria Municipal de Educação/Divisão de Estudos e Projetos/EPAZ em Goiânia e Técnico Pedagógico da Superintendência de Ensino Médio da Secretaria Estadual de Educação em Goiânia. E-mail: titocoelho2000@yahoo.com.br.

${ }^{2}$ Professor Associado no DEGEO/UFJF, pesquisador do NuGea/UFJF, colaborador no Programa de PósGraduação em Geografia do IESA/UFG. E-mail: carlmaia@uol.com.br.
} 
viaje o inflexión de la folía de Reyes, fiesta popular del ciclo de Navidad que reproduce el viaje de los Tres Reyes Magos del Oriente en el camino a Belén, a fin de comprender el rescate de las tradiciones rurales de la relación casa-calle en el contexto urbano. Se dialoga, en el texto tanto con autores de la Geografía como de otras ciencias humanas, a fin de entender las salidas de folías como fiestas populares. Las discusiones se basan en referencias bibliográficas y en pesquisa de campo participante.

Palabras Claves: Fiesta popular, interacción espacial, folías de reyes, rituales, fiesta religiosa.

\section{INTRODUÇÃO}

As folias, incluindo as de Reis, são festas comuns em inúmeras cidades brasileiras, tanto quanto no meio rural. No Estado de Goiás, particularmente, costumamse inclusive diferenciar nominalmente as folias, de acordo com seu 'giro', , ou seja, seu percurso ritualizado, em 'folias da roça' e 'folias da cidade'. Ainda que pese a palavra 'cidade' na composição desse último substantivo, as folias, de um modo geral, conforme comentam Almeida (2011) e Silva (1987), são tradições rurais que se inserem no meio urbano. A este respeito, Almeida (2011) adverte:

[...] festas rurais em um meio urbano é uma característica peculiar neste estado [Goiás] que, a despeito de sua urbanização e modernização crescentes, mantém as raízes no rural. No caso da Região Metropolitana de Goiânia (RMG), mesmo com o peso vigoroso de Goiânia, uma metrópole de mais de um milhão de habitantes, nota-se que várias festas permanecem, ainda, com uma característica rural, visto que celebram produtos agrícolas, atividades rurais, o homem ou a mulher com sua prática cultural do meio rural $[\ldots]$.

Já Silva (1987, p. 43 e 45), sobre este mesmo assunto, observa:

O processo caótico na forma de ocupação da Baixada Fluminense quando visto sob a ótica da cultura e do saber populares se revela extremamente rico, apresentando uma harmonia pouco perceptível à cultura dos letrados, sobretudo com fortes conotações dos modos de vida e formas de sobrevivências do homem do campo.

$\mathrm{O}$ surgimento nesta área, em elevado número, das festas tradicionais de origem rural estão a nos exigir uma parada para pensar. A presença das "Folias de Reis", uma manifestação caracteristicamente rural, seu elevado número em Nova Iguaçu pode ser creditada aos fluxos migratórios em direção à região da Baixada Fluminense...

\footnotetext{
${ }^{3}$ Daqui em diante, utilizaremos aspas simples ("), consoante Mesquita (2007, p. 555), "para ressaltar o valor significativo de uma palavra ou expressão"; já que "aspas duplas são empregadas para indicar o início e o fim de uma citação, de modo a diferenciá-la do restante do texto".
} 
Em relação às "Folias de Reis", o município acolhe um substancial número, em se considerando que, no campo, de onde basicamente se originam, a média é de quatro a cinco grupos por cidade ou município.

Cumpre destacar, inicialmente, que os movimentos-rituais na ocasião da saída de folia de Santos Reis são proporcionados pela fé, crença e confiança na Divindade, à qual se recorre mediante promessas e votos com fins diversos. Esses movimentos são indicativos de interações espaciais, dada a transferência de pessoas e coisas entre áreas, que podem ter como uma de suas variáveis implicadoras a distância (ULLMAN, 1974; CORRÊA, 1997). No caso da saída de bandeira, as distâncias relacionadas aos deslocamentos dos participantes são pequenas, mas nem por isso menos importantes aos rituais para os devotos, já que desvelam maneiras de cultivar a sua fé religiosa. Assim, além da distância e da transferência de coisas e pessoas consideram-se neste estudo os rituais: benzeduras, orientações disciplinares, cantorias, rezas, preces e pequenos deslocamentos e posicionamentos.

Destarte, esclarecemos que a saída de folia de Reis traduz interações espaciais por ser um "conjunto de deslocamento de pessoas" (CORRÊA, 1997, p. 279) que se realiza de modo ritualizado entre os espaços da casa para a rua, então ressignificados nessas tradições rurais. Tais deslocamentos ritualísticos, além de movimentos e direcionamentos próprios, são acompanhados de rezas, orações, preces e súplicas cantadas e marcadas temporalmente por silvos de apitos.

O trabalho se inicia com algumas reflexões sobre religiosidade, rituais e contextualização dessa tradição da 'roça' na 'cidade', revisitando-se a casa e a rua como seu espaço de ocorrência. A seguir, pegam-se aqueles marcos temporais, os silvos dos apitos, para a exposição de como as interações vão se materializando e redefinindo o lugar da casa e da rua na cidade no lapso de permanência desta tradição rural, vivificada em práticas ritualísticas.

Para elaborar este trabalho realizamos pesquisa bibliográfica e de campo. $\mathrm{Na}$ pesquisa bibliográfica resgataram-se registros disponíveis, recorrendo-se a trabalhos concluídos por meio de livros, artigos, monografias, entre outros. Na pesquisa de campo, in loco, durante os rituais das saídas da Companhia de Reis do Jardim das Aroeiras, observamos fatos e fenômenos ocorridos durante os deslocamentos dos foliões e buscamos dados a eles referentes. Fizemos uma pesquisa participante de "grande interação entre pesquisador e pesquisados" (ESTRELA, 2005, p. 168), o que possibilitou a incorporação dos foliões como membros ativos do processo de pesquisa. 


\section{RELIGIÃO, ESPAÇO-RITUAL E INTERAÇÃO RITUALIZADA}

Ultimamente, geógrafos culturais têm se preocupado em investigar as práticas espaciais do "homo religiosus" e a importância das religiões em nossos dias. Iniciemos, então, este texto partindo da seguinte premissa reflexiva:

Muitas pessoas sentem-se cansadas de doutrinas religiosas, de reflexões teológicas e de discursos sobre Deus e sobre o Sagrado. Mas escutam atentamente quem fala a partir da experiência de Deus. Elas mesmas querem sentir Deus ou fazer aquela experiência, interpretada como sendo a emergência de Deus. Então, perguntam-se: como experimentar Deus e Ter um encontro com Ele? (BOFF, 2000, p. 145)

Assim, ao tratar da questão espaço sacro-profano, Raffestin (1993, p. 119), à semelhança de Boff, considerou que, "do mesmo modo que a língua, a religião é um sistema sêmico, cuja função é assegurar uma mediação". Ou seja, mediação do homem (profano) com Deus (sagrado) ou do homem com o sobrenatural. Dessa maneira, podemos observar que há interação entre homens e seres divinos de um modo geral na sociedade, a qual aufere distintas formas de poder àqueles. Tal interação diz respeito a relações de poder por distinguir, de imediato, o espaço sagrado do espaço profano ${ }^{4}$. Há relações recíprocas (relativas às interações espaciais) no espaço sagrado intermediadas pelos fatos culturais, isto é, embora os espaços sagrado e profano sejam distintos, ao mesmo tempo eles se "embaraçam”, especialmente nos rituais e na dimensão mítica do catolicismo popular (MAIA, 2010, 2011).

Assim, a religião administra as coisas sagradas, sendo, ainda, um instrumento eficaz de comunicação e comunhão dos indivíduos, já que há produção e circulação de mensagens sagradas durante os rituais. Ao perceber a complexidade do fato religioso como elemento histórico, Eliade (1996, p. 27) elucida que "a mais nobre mensagem religiosa, a mais universal experiência mística, o mais comum dos comportamentos humanos - como, por exemplo, o temor religioso, o rito, a prece - singularizam-se e delimitam-se à medida que se manifestam".

\footnotetext{
${ }^{4}$ Segundo Eliade (1996, p. 27), "a primeira definição que se pode dar ao sagrado é que ele se opõe ao profano" (2001: 17). Para o autor, é possível conhecer o sagrado, porque se manifesta e se mostra como diferente do profano, em forma de hierofania: algo de sagrado se revela. Pode-se dizer, então, que são manifestações das realidades sagradas em objetos, pedras, árvores (hierofania elementar) ou a encarnação de "Deus em Jesus Cristo" (hierofania suprema), conhecida como Epifania do Senhor. Também Rosendahl adverte que "o ser humano, ao aceitar a hierofania, experimenta um sentimento religioso em relação ao objeto sagrado".
} 
Estudar as interações espaciais no 'espaço-ritual' das folias é uma forma de se pensar a movimentação de pessoas em espaços festivo-religiosos. Por isso, o estudo dos conceitos de rito e ritual são 'luzes' para a compreensão desse processo. Ferreira (2004, p. 649) define rito como "[...] regras e cerimônias próprias da prática de uma religião [...] culto; religião". Como ritual, o autor argumenta que é "relativo a ritos... liturgia, cerimonial, etiqueta". Já Cunha (2007, p. 686) conceitua rito como "conjunto de regras e cerimônias que se devem observar (na prática de uma religião)”. Durante a saída de uma folia, é possível observar várias regras ritualísticas desde a chegada dos foliões ('beijamento' da bandeira) até a saída para as ruas.

O ponto de origem dos deslocamentos da folia de Reis tem como base o movimento da casa dos foliões para a casa do capitão ou do festeiro nas vésperas, no dia ou durante o levantamento da bandeira. Na folia pesquisada, a casa do capitão fica aberta aos foliões que chegam de Itauçu, Cesarina, Aparecida de Goiânia (os mais destacados), de vários bairros da cidade e do Jardim das Aroeiras. Assim, a folia é formada por "movimentos e passagens diversos" (DAMATTA, 1983, p. 79), marcados pelo ritmo dialético da casa e da rua; da devoção-fé e decisão de deslocar pela vontade de estar na folia. Suspende-se ainda, na sua ocorrência, o tempo frenético-mecânico da vida urbana e retoma-se o tempo cíclico subordinado à lógica do pensamento mítico, em que se fundem "o momento-coisa e o momento significação" (MAIA, 2011) típico de tradições rurais, o que reafirma a folia como festa rural no meio urbano, como já mencionamos.

Apesar dessa temporalidade regida pela lógica mítica, o tempo do folião urbano acaba refletindo uma 'folga' e sua passagem para outro setor (bairro) adequa-se ao frenesi ou rush hour dos ônibus ou do trânsito caótico, que os fazem levantar cedo e se colocarem em marcha em direção à folia e 'seu tempo-espaço'. A passagem da casa onde se mora para aquela onde sai a folia é o momento da pressa em ir para a festa freada pela lentidão do fluxo de veículos, pela rotina da cidade, mas o que importa é ir para sair de novo, ou seja, direcionar-se à saída da folia. DaMatta (1983, p. 79) ressalta que "no mundo ritual, ou melhor, no mundo deslocado do rito e da consciência, ocorre, - parece-me - uma diferença fundamental: é a marcha que se torna importante [grifos do autor]". O deslocamento de casa para o trabalho, seja de carro próprio, ônibus, bicicleta ou a pé, é uma ação mais inconsciente e banalizada (rush hours), mas o giro, a 
peregrinação, a jornada por devoção ou festividade religiosa ${ }^{5}$ é revestida de sentido simbólico, em que caminhar e chegar geram sentimentos mágicos no peregrino. É diferente da marcha funcional, racional e operacional para o 'trabalho' cotidiano: prestar serviços, negociar, estudar e se sustentar. Assim, enquanto um torna-se costumeiramente apropriado por uma obrigatoriedade 'enfadonha' (o deslocamento rotineiro), o outro, o festivo, é norteado também por uma obrigatoriedade, mas 'esperada'; e isto porque, como exara Parkin, ritual define-se como uma "fórmula que é levada, em um espaço dado, por um grupo de pessoas que são conscientes da sua natureza imperativa ou obrigatória e que podem ou não posteriormente informar essa característica espacial com palavras faladas" (1992: 18).

Ao estudar os ritos nas folias de Reis, Porto (1992, p. 28) afirma que "o homem sempre cria ritos. As diversas manifestações folclóricas têm os seus ritos. As Folias de Reis também têm os seus". O espírito religioso anima e motiva o deslocamento dos foliões, pois "o espírito de fé e a disposição para o sacrifício animam todas as atividades de um folião" (idem, ibidem). Paralelamente, Tremura analisa as relações de fé dos foliões e o elo destes com os Santos Reis a partir da interligação dos versos das toadas. As cantorias podem ser interpretadas de forma individual ou em combinações casuais. O autor também dividiu e conceituou os rituais de folia de Santos Reis em sete tópicos analíticos interligados nos versos-rituais:

(1) Crença. Este é a razão fundamental da tradição (raison d'etre); (2) Fé. A crença na religião e nos Reis Magos; (3) Ritual. Este é o giro sagrado, no qual os participantes reencenam a viagem feita pelos Reis Magos até a manjedoura; (4) Família. Que não é limitada a laços de sangue, mas inclui parentes e amigos próximos; (5) Expectativa Social. Está relacionado aos ensinamentos e valores cristãos como o de reciprocidade, respeito, e humildade; (6) Conduta Social. Este tópico expressa o comportamento dos participantes na sociedade como os mensageiros dos Reis Magos na Terra; (7) Agradecimento. Neste tópico os participantes chegam a uma visão de equilíbrio entre o mundo material e o espiritual. (TREMURA, 2004, p. 4)

Se interações espaciais são conexões entre lugares, por meio da transferência e deslocamento de coisas, pessoas e informação, podemos analisar a forma com que isso

\footnotetext{
${ }^{5}$ Ao definir o conceito de religião, Durkheim constatou que a espiritualidade de toda espécie e de toda ordem, com a qual os povos atribuíram sentido à natureza, são objetos de ritos ou de culto regular. Os ritos e rituais são realizados 'por devoção' a um Ser Espiritual: As almas dos mortos, os espíritos de toda espécie e de toda ordem, com que a imaginação religiosa de tantos povos diversos povoou a natureza, são sempre objeto de ritos e, às vezes, até de um culto regular; no entanto não se trata de deuses no sentido próprio da palavra. Mas, para que a definição os compreenda, basta substituir a palavra Deus pela de ser espiritual, mais abrangente (DURKHEIM, 2000, p. 11).
} 
ocorre nos rituais trovados das folias de Reis. Maia (2010) esclarece que, nos rituais, as pessoas em deslocamento ritualístico são copresenças, ou modos de ser-no-mundo, ao reconhecer também o outro como ser-no-mundo. No processo ritual há passagem do individual ao coletivo e o participante se vê na qualidade de ser-com juntamente com os demais, distinguindo-os dos estranhos. Há diferenciações entre indivíduos, não havendo somente harmonia entre os partícipes no modo de ser no ritual; socialmente, vão surgindo hierarquias, negociações, resistências às ordens, conflitos e tensões (MAIA, 2010).

De acordo com o exposto, infere-se que as interações espaciais na folia podem ser analisadas mediante a fé, a crença, a devoção aos Santos Reis e os movimentos promovidos pelos rituais cantados, havendo ausência sensível da autoridade clerical, o que aponta também a sua dimensão de 'tradição rural' ${ }^{6}$. Nestes podem ser observados os direcionamentos e os posicionamentos espaciais proporcionados pelo deslocamento da bandeira, dos versos trovados e de outros movimentos pertinentes. Outras regras de direcionamento se dão na saída da bandeira, no almoço e no pouso, no agradecimento de mesa e outros. Os componentes da folia seguem um posicionamento na realização da cantoria. Todos os participantes, o devoto, o embaixador, os integrantes do coral de $1^{\mathrm{a}}$ à $6^{\mathrm{a}}$ voz e os responsáveis pela percussão obedecem a uma posição, o que ratifica a dimensão essencialmente espacial dos rituais e a ressignificação da casa durante a folia: não é a casa da 'cidade' cercada, cerceada e sitiada na impessoalidade; mas sim a casa rural da prosa, da cantoria, da comilança compartilhada.

As interações espaciais, no processo ritual da folia estudada, consistem no deslocamento de parte dos foliões para a casa do capitão um dia antes da saída da bandeira; ajustes com embaixadores; dos foliões para a casa do festeiro para tomar café (no dia da saída), receber o uniforme composto de uma camisa e uma toalha como divisa na folia; a saída é o início da viagem. Nesses dias, os foliões se encontram na casa do festeiro do ano para começarem a peregrinação (CANESIN e SILVA, 1983). A toada de saída da bandeira "é cantada no momento que os participantes presentes na casa do festeiro (responsável pela festa do dia de Reis) se despedem do altar (quase sempre um presépio), antes da saída para o giro" (TREMURA, 2004, p. 4).

\footnotetext{
${ }^{6} \mathrm{O}$ catolicismo popular rural, especialmente no 'sertão goiano', desenvolveu-se à margem da Igreja, fosse pela dificuldade de alocar bispos, prelados e padres, fosse pela distância a ser percorrida entre as fazendas, ou, ainda, pelo descaso dos representantes clericais com o que consideravam 'exterioridades' (MAIA, 2002).
} 


\section{O PRIMEIRO APITO, BENZEÇÃO E RECOMENDAÇÕES}

Antes de discutir os movimentos-rituais de saída esclarecemos que a fluidez entre os fixos é marcante nos giros de folia. Neles fixos e fluxos interagem e se alteram mutuamente, percebendo-se uma realidade geográfica própria nos rituais cantados. Sugerimos aqui que fixos e fluxos, além de se constituírem como base analítica das redes numa dimensão técnico-científico-informacional (SANTOS, 1996) a compõem ontologicamente. Ou, de outra forma, os fixos e fluxos formam redes geográficas em sua dimensão ôntico-ontológica. É nesse sentido que Maia (2002) esclarece a natureza dos fluxos e fixos baseado em Dolffus e Heidegger. Para nós, tal concepção permite propor que o fluxo de pessoas em copresença nos rituais de folia redimensiona os fixos, dando-lhes novos significados, tornando-os pontos referenciais de festas rurais inseridas no meio urbano (ALMEIDA, 2011; SILVA, 1987). Vejamos a seguir os movimentos do ritual de saída da bandeira da Companhia de Santos Reis do Jardim das Aroeiras em Goiânia.

Ao primeiro apito, os foliões devem ficar em silêncio e se movimentarem para o presépio e a bandeira, a fim de serem bentos pelo capitão ${ }^{7}$ (Figura 01). Isso "cria uma centralidade temporária que transforma a vida dos moradores" (COSTA, 2010, p. 92), muda o uso da sala ou do espaço onde está o presépio, torna a casa um espaço sagrado; se houver pedido, reza-se o terço.

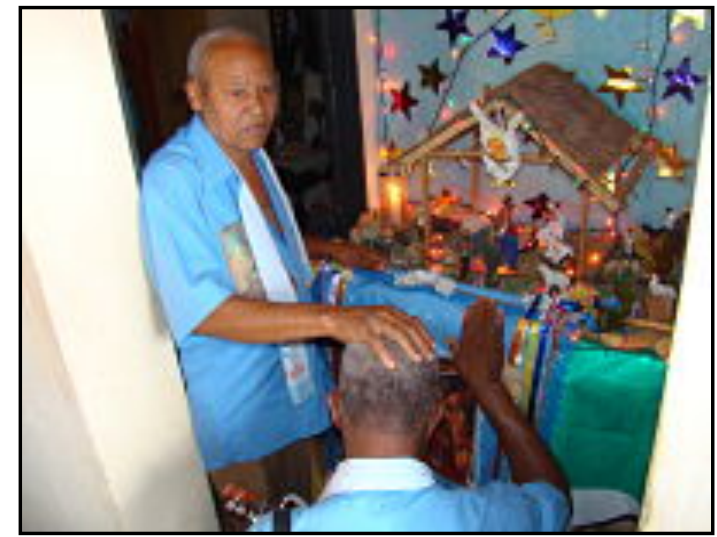

Figura 01 - Benzedura da companhia antes de sair para as ruas. Foto: Tito Coelho, 2010.

\footnotetext{
${ }^{7} \mathrm{Na}$ folia pesquisada, o recurso da benzedura é, em geral, muito utilizado, fazendo com que capitão seja considerado uma espécie de curandeiro. Isso provoca grande procura pelo capitão da folia quando se sente uma dor (de cabeça, de dente) ou outro incômodo. As pessoas se deslocam até ele durante a folia e a qualquer dia fora dela. As habilidades sociais, o carisma e os dons espirituais do capitão são muito diversificados, o que cria um fixo, ou melhor, uma centralidade temporária em torno da sua pessoa, alguém em quem buscar aconselhamento, curas e formação espiritual.
} 
É o capitão que dá as advertências em relação às obrigações religiosas dos rituais nas casas em geral, controla horários de chegar e sair (para sair têm-se, necessariamente, que avisá-lo), vigia o uso de bebida alcoólica e observa as vozes para colocar cada participante em sua posição adequada, com o intuito de harmonizar a cantoria. Desse modo, as crenças que regem a esfera sagrada normatizam o comportamento ritual e atuam promovendo oportunidades intervenientes.

\section{O SEGUNDO APITO, POSICIONAMENTO E CONTROLE}

Ao segundo apito, o embaixador chama os foliões para tomarem suas posições na seguinte ordem: alferes, embaixador, primeira a sexta vozes, pandeiristas e caixeiro, a fim de dar início à cantoria de saída da bandeira da casa do festeiro, repetindo-se o mesmo ritual a cada manhã, na saída do pouso de janta. Esse momento simboliza a saída dos Três Reis Magos em direção à luz da Estrela Guia. O embaixador exerce o controle movimento-deslocamento do grupo por meio dos versos cantados ao longo dos rituais.

Em seu discurso sobre a interação e o controlo no sistema social, Rémy e Voyé (1994, p. 28) exaram que "se se entender por interaç̧ões as interdependências que resultam de actividades colectivas, o sistema social será a organização destas com referência a prioridades que definem o lugar do poder e a sua capacidade de controlo". Já para Raffestin (1993), a mobilidade é de difícil controle pelas organizações interessadas em modificar a repartição e a distribuição dos homens no espaço. É mais fácil analisar as relações de força que provocam a mobilidade do que a natureza que a determina:

Se não é fácil controlar a natalidade e a mortalidade, também não é simples controlar a mobilidade, ainda que isso dependa dos meios de que dispõem as organizações interessadas em modificar as repartições, as distribuições dos homens no espaço [...] De fato, é mais importante analisar as relações de força que provocam a mobilidade do que a natureza daquilo que a determina, como, por exemplo, a guerra ou o trabalho. Diremos que a mobilidade é autônoma quando resulta de uma escolha deliberada, e heteronômica quando resulta de uma coerção. (RAFFESTIN, 1993, p. 88)

O deslocamento para os fixos conectados na folia pode ser visto como uma imposição, mas, também, como um desejo de comungar com a divindade, resgatar o 
pertencimento a outra realidade (rural), sentir-se útil, obter ânimo para retornar ao cotidiano ou mesmo exercer alguma forma de poder, combinando, assim, autonomia e heteronomia. O controle aí se exerce algumas vezes na relação entre sujeitos, pois há observações e comentários personalizados dos indivíduos, no sentido de vigilância recíproca benevolente ou malevolente ao se praticar a solidariedade, a confiança e a simpatia mediante a relação interpessoal. Assim, na folia, a autoridade tradicional, ainda bastante presente na cultura rural, prevalece sobre a legal, predominante na realidade urbana.

Os Três Reis Magos se tornaram santos (como se diz) pelo fato de terem percebido a Estrela, ou a Luz Divina, e a terem seguido até a gruta, manjedoura, lapinha ou estábulo, lugar onde nasceu o Filho de Deus. Reiterando as palavras de Dumont (2000, p. 27), “[...] eles viraram santos porque souberam que alguém muito especial estava nascendo para salvar a humanidade". Como essa peregrinação é reproduzida pelos foliões, podemos dizer que ela também os abençoa ao passar de casa em casa anunciando o Nascimento de Jesus Cristo: "da mesma forma como a jornada dos Três Reis os santificou, a folia é uma prática religiosa e santificante, porque reproduz simbolicamente a viagem dos santos cultuados. Ela é percebida como uma situação ritual adequada e suficiente para o cumprimento de obrigações religiosas e devocionais" (BRANDÃO, 2004, p. 383). Sugerimos, também, que a interação espacial dos Reis Magos os 'santificou' e, assim, realizar o giro ou jornada da folia de reis em deslocamento, movimento e transferência de pessoas e coisas de um lugar para outro é uma forma de santificar os fixos e fluxos ao longo da trajetória percorrida. Tal aspecto ressalta também o elo rural das folias que ocorrem na cidade, pois os "sertões", durante um longo período da nossa história, foram preteridos pela Igreja e visitados somente em ocasiões especiais (visitas prelatícias e episcopais e festas populares). Com isso, os cultos nas casas, diante de oratórios, presépios e bandeiras, por exemplo, substituíram na 'roça' a 'ida às igrejas', dispostas nas vilas e cidades. Assim, a folia de Reis, enquanto encontro com o presépio, é também um retorno dessa forma de catolicismo popular tão comum antanho nos 'sertões', em que certos nichos na casa (oratórios) eram tidos como lugares sagrados. 


\section{O TERCEIRO APITO: LEVANTAMENTO DA BANDEIRA E DESLOCAMENTO}

No terceiro apito iniciam-se os pequenos deslocamentos da saída da bandeira: o embaixador apita chamando a atenção para a introdução da cantoria. É um momento de muita expectativa, concentração e emoção dos foliões. Na análise de Tremura (2004, p. 3-4) as toadas de folia de Santos Reis apresentam poesia popular, rima e, por meio delas, "fortalecem as relações pessoais, expressam devoção, e cumprem promessas feitas pelos participantes aos Reis Magos com o intuito de ajudar ou favorecer familiares com problemas financeiros ou de saúde". Os versos apresentam grande poder de articulação no tocante à formação de ideias, interpretação do tempo-espaço sagrado e de ligação com os Santos Reis como mediadores dos homens com Deus (TREMURA, 2004). Assim cantam-se os versos de invocação da Santíssima Trindade, de benzeção para livrar dos males que vêm, oração, bênção dos Reis, chamando os foliões para viajarem com destino a Belém, no sentido de visitar o Menino Jesus simbolicamente:

\footnotetext{
Pai e Filho e Espírito Santo,

Vamo nóis benzê primeiro

Vamo nóis benzê primeiro,

Pra livrar do mau que vem

Pai Nosso, Ave Maria,

A oração foi Deus que feiz

Nois tá sen'abençoado,

Pelo glorioso Santo Rei

Vamos nóis segui viage,

Com destino a Belém

Visitá Menino Deus,

Que nasceu pro nosso bem
}

Depois de convidar os foliões para a viagem, o embaixador adverte o 'senhori' ou a 'senhora' (no caso da saída, um ou os dois festeiros) dono ou dona da casa e pede para levantar a bandeira. É um momento de comoção para todos, pois a bandeira simboliza os Magos, São José, Santa Maria e o Senhor Jesus Cristo recém-nascido. Tremura (2004, p. 6) observa a hierarquia sagrada nos versos: "na tradição da folia de reis a ordem hierárquica dos seres divinos costuma ser observada quando são feitas referências a Deus, Jesus, Maria, José e os Reis Magos respectivamente". Notamos, porém, que os versos na folia estudada não seguem uma ordem hierárquica precisa a fim de se dar rima às toadas: 


\begin{abstract}
Pra nóis segui viage,
Alevanta nossa guia.

Santo Rei alevantô,

São José e Santa Maria

Pra cumpri uma missão,

Deste filho de Maria.
\end{abstract}

Após o festeiro, o palhaço (pastorinho) é chamado para fazer sua obrigação (ajoelhar-se diante da bandeira já 'levantada' pelo dono da casa), beijar a guia e verificar o estado da bandeira para poder entregá-la do mesmo jeito que a pegou para vigiar $^{8}$. Os foliões são advertidos, de forma cantada, para refletir sobre a responsabilidade que estão assumindo, juntamente com o alferes. Todos são responsáveis pela vigilância da bandeira dos Três Reis Santos por onde ela andar:

$$
\begin{aligned}
& \text { Veja a responsabilidade, } \\
& \text { Que acabamo de pegá } \\
& \text { O oferi da bandeira, } \\
& \text { Também tem que vigiá } \\
& \text { A bandera dos Treis Rei, } \\
& \text { Por onde ela andá. }
\end{aligned}
$$

Depois dos versos de advertência iniciam-se os versos de despedida: os festeiros se despedem da bandeira e os foliões se despedem do presépio. Logo, em seguida, o embaixador recua à sua direita, juntamente com os foliões, convidando os festeiros a se deslocarem do presépio (na folia temporã, ou fora do tempo, há, no lugar deste, o altar para trovar) até a porta de saída, para que os demais o acompanhem.

Na saída da bandeira, o embaixador e os foliões fazem um recuo para a direita para que, à sua esquerda, o festeiro, ou no caso de almoço e pouso, os donos da casa possam sair com a bandeira e fazer uma parada à porta. Depois de passados os vigias, o embaixador canta que, com o poder dos Três Reis Santos, a companhia vai embora e, finalizando a cantoria, toda a companhia passa sob a bandeira beijando-a. Após todos terem passado e beijado a guia, o alferes passa a conduzi-la, mediante olhares do palhaço: “desse momento em diante ela estará 'em jornada' ou 'no giro' até o dia 6 de janeiro" (BRANDÃO, 1977, p. 22).

O embaixador pede aos donos da casa para fazerem uma parada na porta, então benze a companhia. Esse momento causa uma espécie de nostalgia aos donos da casa, por se despedirem dos Santos até o dia da entrega; e aos foliões, por estarem iniciando a jornada ou o giro:

\footnotetext{
${ }^{8}$ Vejamos os versos: "Pastorinho de Oliveira, da uma chegada prá cá; já cumpriu sua obrigação, Pode se alevantá; arrepara essa bandeira, veja como ela está; do jeito que ela saí, nóis devemo entregá”.
} 
Ocêis despede da bandeira,

Nóis despede da lapinha

Vai saino com a bandeira,

Pra nóis acompanhá

Na porta faz uma parada,

Pra benzer a companhia.

Finalmente, iniciam-se os versos de movimento para a rua e a peregrinação pelas casas. O embaixador ordena, de forma cantada, que os palhaços passem sob a bandeira, vigiando, assim, a saída dos foliões e demais presentes que estejam no 'salão' do festeiro (Figuras 02 e 03):

La do céu já deu sinal,

Vô passá os meu vigia

Com o poder dos Treis Rei Santo,

Vamo simbora companhia

Pai e filho, Espírito Santo,

Para sempre amém, amém.
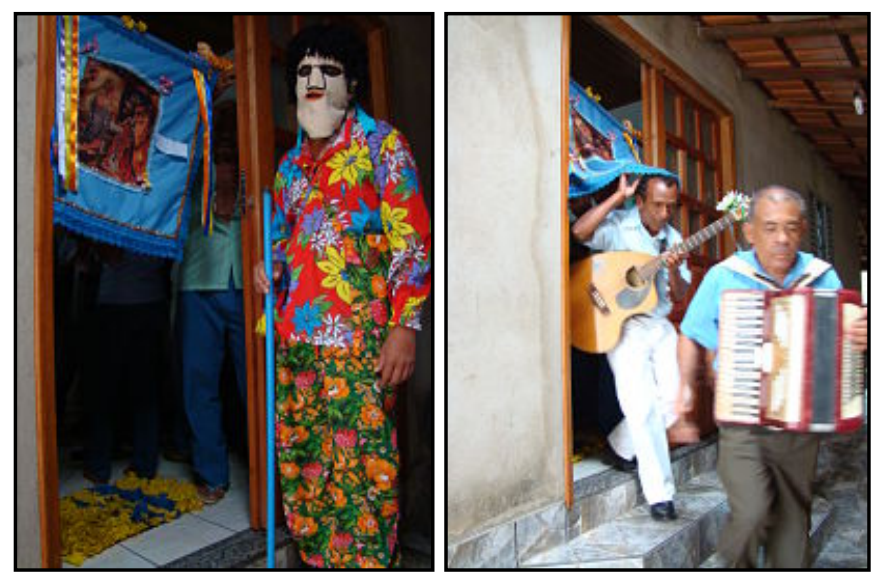

Figuras 02 e 03 - Palhaço guiando a bandeira e a saída dos foliões ao término do ritual de saída da bandeira.

Foto: Tito Coelho, 27 de janeiro de 2009.

\section{O QUARTO APITO: FIM DA CANTORIA E OS VIVAS}

Antes das respostas (vozes) ao último verso, o embaixador apita pela quarta vez, chamando os músicos para o breque da toada. Finalizada a cantoria, os palhaços logo bradam: "viva os Três Reis do Oriente", todos respondem fortemente: viva. Dão-se vivas à Sagrada Família, aos foliões, aos festeiros e aos convidados para a saída. Então, "no final da toada os participantes se posicionam com a bandeira na frente do cortejo e se direcionam a rua" (TREMURA, 2004, p. 6). É nesse momento que as interações 
espaciais do giro propriamente dito se iniciam, ou seja, na transferência da companhia para a rua em direção às casas que serão visitadas, retornando ao mesmo lugar, casa do festeiro, posteriormente completando o ciclo do giro, como esquematizado na Figura 04.

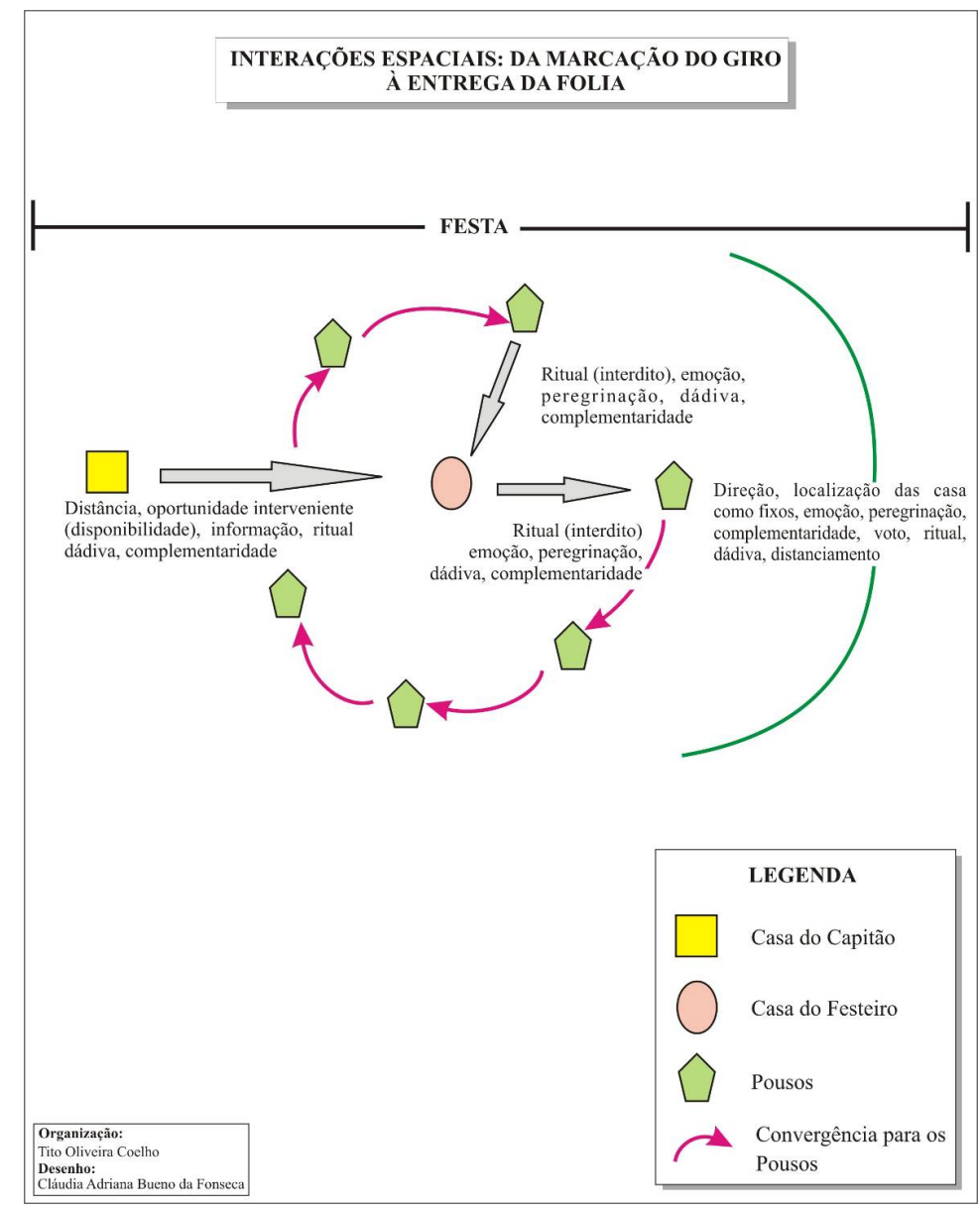

Figura 04 - Croqui da interação espacial da marcação do giro à entrega da folia. Fonte: Trabalho de campo de Tito Coelho 2010/11.

A saída da bandeira da casa do festeiro (no início do giro) marca a separação ou transição entre o deslocamento dos foliões de casa para peregrinar e a peregrinação propriamente dita. É o ponto em que há a sacralização dos movimentos, deslocamentos, mobilizações e o tempo em que o ritual é dedicado aos Santos Reis. Todos os participantes são envolvidos pelo giro para transportar pessoas, girar e preparar a grande festa final. É o momento em que as pessoas "são transferidas do mundo secular e profano para o domínio do extraordinário" (PEREIRA, 2009, p. 9) e, sem que percebam, vão perdendo pouco a pouco a noção do tempo cotidiano, tudo parece ser aqui e agora (plenitude) sem se preocupar com o relógio, horas, minutos e segundos. Os foliões, ou parte deles, ficam em estado de suspensão da consciência, em que os 
"trabalhos cotidianos são temporariamente encerrados" (idem, p. 9) e vivem seus momentos de coparticipação na devoção a Belchior, Gaspar e Baltazar, figurando os seguidores de Deus à procura de seu Filho: o Menino Jesus. Para isso, solicitam férias ou mesmo se ausentam de seu trabalho.

O giro, a jornada ou a peregrinação dos foliões reproduzindo a viagem dos Reis é a "essência do ritual" (idem, p. 9), momento em que as pessoas cumprem o 'contrato' ou promessa com os Santos Reis de várias formas. O grupo, que sai pelo lado direito, chegará no dia da festa de entrega da bandeira pelo lado esquerdo da casa do festeiro, fechando o giro. O movimento obedece a uma orientação solar, pois, saindo pela direita, chegarão pela esquerda, mesmo que o lado direito da porta seja o lado oposto do Oriente. Nesse caso, a folia desce um pouco do lado que saiu, podendo passar por algumas casas, mas, atravessando para o outro lado da rua, passa pelo Leste primeiro, segue para o Oeste e retorna, de forma que fique uma rua sem que a bandeira por ela tenha passado para que se possa chegar pelo lado esquerdo da casa. Dessa forma, não se fecha o circuito do giro.

\section{CONSIDERAÇÕES FINAIS}

Ao longo do texto, procuramos demonstrar como movimentos rituais da saída de uma folia de Santos Reis promovem interações espaciais através da fé, da devoção e da emoção no tempo-espaço do levantamento da bandeira, que traduzem um enraizamento na 'cidade' de tradições da 'roça'. Tais movimentos não se baseiam em uma lógica operacional urbana, mas mítica, a qual fundamenta manifestações de religiosidade popular interligando casa e rua, fixos e fluxos, divindades e devotos mediante tradições rurais, crença e voto.

A jornada da Companhia de Santos Reis do Jardim das Aroeiras em Goiânia é recebida por famílias de origem rural na Região Leste desta cidade, bem como boa parte de seus componentes mais antigos e guardiões da tradição possuem tal ascendência, tendo a festa como forma de manter suas raízes camponesas. Notamos essas características por meio da linguagem popular - parte da diversidade linguística brasileira -, das comidas servidas em grandes panelas (arroz, feijão, macarrão, guariroba, carnes de bovino e suíno, legumes), dos toldos nos quintais da casa, das melodias chamadas de toadas, da refuncionalização da casa e da dinâmica espaço-tempo 
na festa. É uma celebração em que se revisita o modo de ser camponês na cidade num espaço-tempo em que homens e mulheres manifestam sua cultura e enraizamento na 'roça'. O processo de ocupação da Região Leste de Goiânia por pessoas de origem camponesa permitiu a formação do grupo de foliões aqui analisado, grupo este que interage com devotos moradores dos vários 'bairros' que percorrem, mormente com esta mesma origem.

Ainda que o grupo de folia de Reis do Jardim das Aroeiras seja assediado por estudiosos e pela mídia, a preocupação com as tradições suplanta a espetacularização, seguindo-se os rituais de acordo com o que determina o capitão, e não por tal ou qual busca de promoção midiática. Isto ratifica, a nosso ver, que o resgate de um modo de ser rural é mais importante para o grupo que os valores urbanos de sucesso, notabilidade e fama.

O resgate dessa tradição da 'roça', qual seja, a peregrinação dos Três Reis Magos do Oriente até a Lapinha de Belém, nos faz ver que a 'viagem' é o motivo principal de uma interação espacial complexa na atualidade, promovendo transcendência com o cotidiano e estabelecendo relações societárias específicas, traduzidas, por exemplo, em relações de autoridade próprias nos espaços em que se realiza. Assim, propomos neste trabalho que a saída de uma folia de Reis é parte de uma ‘jornada bem maior' e mostramos que cada um de seus rituais é dotado de deslocamentos, movimentos e gestos distintos produzidos na situação festiva que ressignifica a casa e a rua a partir de forças míticas que permeiam a convergência de fluxos e fixos, da roça e da cidade, de um a outro bairro, de uma casa a outra; enfim, de uma jornada diária a outra festiva.

\section{REFERÊNCIAS}

ALMEIDA, Maria Geralda de. Festas Rurais e Turismo em Territórios Emergentes. Biblio 3W. Revista Bibliográfica de Geografía y Ciencias Sociales, Universidad de Barcelona, v. XV, n. 918, 15 de abril de 2011. Disponível em: http://www.ub.es/geocrit/b3w-919.htm. Acesso em: 28 abr. 2012.

BOFF, Leonardo. A voz do arco-íris. Brasília: Letraviva, 2000. 
BRANDÃO, Carlos R. A folia de Reis de Mossâmedes. Rio de Janeiro: ArteFUNARTE, Campanha de Defesa do Folclore Brasileiro, Departamento de Assuntos Culturais, MEC, 1977.

. De tão longe eu venho: símbolos, gestos e rituais do catolicismo popular em Goiás. Goiânia: Editora da UFG, 2004.

CANESIN, Maria T.; SILVA, Telma C. da. A folia de Reis de Jaraguá. Goiânia: Centro de Estudos da Cultura Popular, UFG/ICHL, 1983.

CÉSAR, Getúlio. Crendices: suas origens e classificação. Rio de Janeiro: APEX GRAFICA e EDITORA, 1975.

CORRÊA, Roberto L. Interações espaciais. In: CASTRO, Iná E. de; GOMES, Paulo C. da C; CORRÊA, Roberto L. (Orgs.). Explorações Geográficas. Rio de Janeiro: Bertrand Brasil, 1997. p. 279-318.

COSTA, Carmem L. Cultura, religiosidade e comércio na cidade: a festa em louvor a Nossa Senhora do Rosário em Catalão - Goiás. 2010. 214f. Tese (Doutorado) Faculdade de Filosofia, Letras e Ciências Humanas da Universidade de São Paulo, Departamento de Geografia, São Paulo, 2010.

CUNHA, Antônio G. Dicionário etimológico da língua portuguesa. Rio de Janeiro: Leixikon Editora Digital, 2007.

DAMATTA, Roberto. Carnavais, malandros e heróis: para uma sociologia do dilema brasileiro. Rio de Janeiro: Zahar Editores, 1983.

DUMONT, Sálvia. O Brasil em Festa. São Paulo: Companhia das Letrinhas, 2000.

DURKHEIM, Émile. As formas elementares da vida religiosa: o sistema totêmico na Austrália. São Paulo: Martins Fontes, 2000.

ELIADE, Mircea. Imagens e símbolos: ensaio sobre o simbolismo mágico-religioso. São Paulo: Martins Fontes, 1996.

ESTRELA, Carlos. Metodologia científica: ciência, ensino, pesquisa. São Paulo: Artes Médicas, 2005.

FERREIRA, Aurélio B de H. Mini Aurélio: o mini dicionário da língua portuguesa. Rio de Janeiro: Nova Fronteira, 2004. 
MAIA, Carlos E. S. Enlaces Geográficos de um Mundo Festivo - Pirenópolis: a tradição cavalheiresca e sua rede organizacional. Tese (Doutorado em Geografia). Rio de Janeiro: PPGG/UFRJ, 2002.

. Ritual e emoção nas interações espaciais: repensando o espaço sagrado nas festas populares de romarias e folguedos. In: ROSENDAHL, Zeny (Org.). Trilhas do sagrado. Rio de Janeiro: EdUERJ, 2010.

. Paisagens festivas e interações mítico-ritualísticas em práticas tradicionais do catolicismo popular. Espaço e Cultura, Rio de Janeiro: UERJ, n 30, p. 19-35, 2011.

MESQUITA, Roberto Melo. Gramática da língua portuguesa. 9. ed. São Paulo: Saraiva, 2007.

PARKIN, D. Ritual as spatial direction and bodily division. In: COPPET, D. Understanding ritual. Londres: Routlege, 1992. p. 11-25.

PEREIRA, Dario. Os peregrinos da folia: um estudo etnográfico sobre uma festa em movimento no Município de Urucuia - MG. 2009. Tese (Doutorado), Prêmio Sílvio Romero de Monografias Sobre Folclore e Cultura Popular, Rio de Janeiro, 2009.

PORTO, Guilherme. As folias de Reis no Sul de Minas Gerais. Rio de Janeiro: MECSEC FUNARTE, Instituto Nacional do Folclore, 1982.

RAFFESTIN, Claude. Por uma Geografia do poder. São Paulo: Ática, 1993.

RÉMY, Jean; VOYÉ, Liliane. A cidade: rumo a uma nova definição? Lisboa: Afrontamento, 1994.

. A natureza do espaço: técnica e tempo, razão e emoção. São Paulo: Hucitec, 1996.

SILVA, Antônio R da. Folia de Reis na Baixada Fluminense: reprodução das relações sócio-culturais do campo no tecido urbano. 1987. 165 f. Dissertação (Mestrado em Geografia), Programa de Pós-Graduação em Geografia da Universidade Federal do Rio de Janeiro/UFRJ, Rio de Janeiro, 1987.

TREMURA, Welson A. A música caipira e o verso sagrado na folia de Reis. Anais do $V$ Congresso da Seção Latino-Americana da Associação Internacional para o 
Estudo da Música Popular, Rio de Janeiro, 21-25 jun. 2004. Disponível em: $<$ http://www.hist.puc.cl/iaspm/rio/Anais2004\%20(PDF)/WelsonTremura.pdf $>$. Acesso em: 15 set. 2010.

ULLMAN, E. L. Geography as spatial interaction. In: ELIOT-HURST, M. E. (Ed.). Transportation Geography: Comments and Readings. New York: McGraw-Hill, 1974. 